\title{
Numerical optimisation of thermoset composites manufacturing processes: A review
}

\author{
G. Struzziero ${ }^{a^{*}}$ J. J. E. Teuwen ${ }^{\mathrm{a}}$, A. A. Skordos ${ }^{\mathrm{b}}$
}

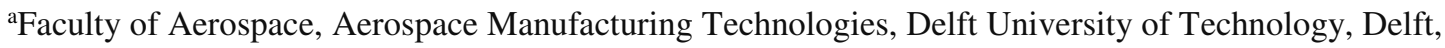
2629 HS, Netherlands

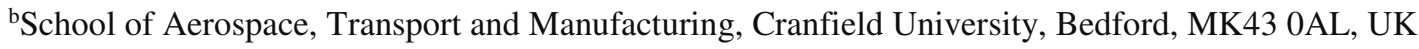

*corresponding author's email: G.Struzziero@tudelft.nl; tel: +31 (0) 152781215

\begin{abstract}
The impetus for higher performance, robustness and efficiency in the aerospace, automotive and energy industries has been reflected in more stringent requirements which the composite manufacturing industry needs to comply with. The process design challenges associated with this are significant and can be only partially met by integration of simulation in the design loop. The implementation of numerical optimisation tools is therefore necessary. The development of methodologies linking predictive simulation tools with numerical optimisation techniques is pivotal to identify and therefore develop optimal design conditions that allow full exploitation of the efficiency opportunities in composite manufacturing. Numerical and experimental results concerning the optimisation techniques and methodologies implemented in literature to address the optimisation of thermoset composite manufacturing processes are presented and analysed in this study.

Keywords: C. Numerical analysis; E. Cure; E. Liquid composite moulding; E. Lay-up (manual/automated)
\end{abstract}




\section{Introduction}

In recent decades composite materials have become a viable and preferred high performance material solution in several fields including the aerospace, automotive and renewable energy sectors. The expansion in utilisation of thermosetting matrix composite materials and the increased geometrical complexity and scale has placed the focus on processing simulation and optimisation to address the demand for maximum product performance at minimum production cost. The complexity of the phenomena involved in composites processing makes a trial and error approach highly inefficient and ineffective. Moreover, the need to comply with strict mechanical performance requirements and tight development time scales highlights the importance of the design stage. In such a scenario, conformity with specifications cannot be addressed at the end of the production line since re-manufacturing work at this stage is, when feasible, costly. Furthermore, the interdependencies between processing stages is such so that defects generated at one stage can affect significantly the success of subsequent steps of the process. Thermosetting composite manufacturing processes generally involve three stages, namely: winding/draping/forming, during which the fibres are placed in the desired lay-up configuration, filling or consolidation, where the reinforcement is impregnated with resin or the pre-impregnated material is consolidated to reach the desirable levels of fibre volume fraction and thickness, and finally curing during which the part undergoes the crosslinking reaction initiated by heating following an appropriate thermal profile.

Fig. 1 summarises defects that can arise at each stage of manufacturing and illustrates their links with subsequent processing steps. Defects at the draping stage include wrinkling, excessive shear and misalignment. These can generate variations in thickness and fibre volume fraction which affect permeability and the filling stage, influence the generation of residual stresses and distortion during cure but also reduce the final quality in terms of mechanical performance. Defects produced during filling and consolidation include resin rich areas, voids and dry spots. These can affect heat transfer during the cure and have an adverse effect on mechanical performance. A poorly designed curing stage can lead to incomplete cure, severe temperature overshoots, unacceptable levels of residual stresses and distortion and cure induced matrix cracking, all of which directly degrade the performance of the final product. Therefore, predictive tools and optimisation methodologies are needed to achieve first time right manufacturing practices and exploit efficiently the resources employed in the process. 
The aim of the present paper is to summarise the state of the art on numerical optimisation of thermosetting matrix composite manufacturing, focusing on the methodologies adopted, the objectives addressed and the design parameters optimised. The current trends in numerical optimisation of composites manufacturing processes are also identified and suggestions for future steps required to cover gaps in the field are offered.

\section{Numerical optimisation methods}

Optimisation methodologies can be broadly classified into two groups: gradient based techniques and zero order search methods. An optimisation methodology that tries to reach the minimum or maximum of an objective function by using its derivatives is called a gradient based technique. This family of techniques can be used successfully when the landscape of the problem is relatively simple, either convex or non-convex. In cases in which the landscape is riddled with local minima and/or maxima the success of gradient based methods depends strongly on the selection of the initial values of the optimisation variables, requiring a priori knowledge of the landscape which is often not available. An example of a first order gradient based technique is the steepest descent method, which is based on the fundamental property of the gradient of a function to point towards the direction of maximum increase.

Unlike gradient based techniques, zero order search methods do not require continuity of the objective function and of its derivatives. The only requirement is that the objective function can be evaluated at any point within the design space selected. These methods use stochastic tools to search for the optimal solution and they tend to converge to global optimum points. However, there is no guarantee about the strict optimality of the solution obtained. Most often zero order methods are inspired by nature and can also be referred to as stochastic algorithms or Evolutionary Strategies (ES). The main benefits of using such algorithms are that they can overcome the limitation of gradient based technique of getting trapped in local minima and they are not sensitive to initial values of design variables. These methods usually start with the generation of a first random set of solutions called population and move towards improved sets of solutions at each algorithm iteration (generation) through the evaluation of current solutions and the use of stochastic operators. The most widely used evolutionary strategies are Genetic Algorithms (GA) [1], Particle Swarm Optimisation (PSO) [2, 3], and Ant Colony Optimisation (ACO) [4, 5]. GAs are based on natural selection concepts. A population of individuals encoded in a string of bits, 
each representing a solution, forms a generation. At each generation the fitness of every solution is assessed based on the optimisation objectives. The best individuals are sent directly to the new generation whilst the remaining become part of a tournament routine for the selection of the parents for the reproduction of new offspring. Two parents generate a new individual by applying mathematical operators that mimic biological processes such as cross-over and mutation. The reproduction process stops once the new population is complete and the overall algorithm stops when a certain stop criterion is met (i.e. maximum number of generations reached). Fig. 2 represents the operation of a GA that deals with multi-objective optimisation problems. PSO is based on mimicking the social behaviour and dynamic movements and communication of insects and birds. Each particle in the search space adjusts its path in the optimisation space according to its own experience related to the objectives of optimisation as well as the experience of other particles. ACO mimics the behaviour of ants when seeking the best path between their colony and a resource. Ants that successfully find the resource lay down pheromone trails. The path with the strongest pheromone trails leads to the optimal solution and the most likely to be followed. In ACO a number of artificial ants build solutions and exchange information about the quality of their solution using a variable that operates as the pheromone. The practice of joining two different algorithms, e.g. a gradient based and a zero order algorithm, has also been used widely. This is done to combine desirable features from each of the methods, e.g. global optimality of an ES solution and fast convergence to a local optimal points offered by a gradient based technique. Table 1 reports advantages and disadvantages of the two main classes of optimisation techniques. Gradient based techniques have the advantage of fast convergence; however, in the case of a landscape riddled with many local minima, they are likely to be trapped in one. Zero search methods on the other hand avoid getting trapped in local minima and are insensitive to initial conditions; however they are computationally expensive. Gradient based techniques can be used when the landscape of the problem is fully known.

Depending on the number of objectives under study, the problem can be defined as a Single Objective (SO) optimisation problem involving one objective, or a Multi Objective (MO) optimisation problem which involves two or more objectives. SO optimisation can be set up to account for more than one objective at once. This is carried using tailored weighted objective functions in which multiple objectives are aggregated in a weighed sum with weights that imply their relative prioritisation. In contrast, MO approaches address the full trade-off between optimisation objectives without prescribing 
the results through prioritisation of the objectives leading to a final optimal efficient front expressed as a Pareto set of solutions. Fig. 3 illustrates the updating of the Pareto archive in a MO optimisation problem. Regarding the filling of the Pareto archive, each non-dominated individual belonging to the current generation is compared with individuals already in the Pareto archive. Four different scenarios can occur:

a) Any individual in the archive dominates the ones in the current generation, therefore, the Pareto archive does not change;

b) An individual is not dominated by any individuals in the archive and it dominates one of them; as a consequence it replaces it;

c) The archive is not full and no dominance occurs then the individual is simply added to the archive;

d) The archive is full and no dominance occurs, then one individual of the pair of individuals with the smallest distance in the Pareto archive is replaced by the new individual. The metric distance is calculated using an Euclidean norm.

\section{Thermosetting composite manufacturing process optimisation}

The following sections review the research efforts up to date in optimisation of the three stages of thermoset composite manufacturing: winding/draping/forming, filling/consolidation and curing. The focus is on the type of optimisation approach implemented, the objectives selected and the design parameters used. An overview of the optimisation landscape is presented in Fig. 4 summarising the objectives addressed in literature for each of the three stages of composite processing. Fig. 5 illustrates a time line reporting the milestones in the field of numerical optimisation of composite manufacturing. The time line highlights the principal trends followed by the research in this field. The first works in the field addressed SO optimisation problems, followed by treatment of competitive objectives simultaneously in a MO optimisation framework, with the most recent trend involving consideration of variability in a stochastic modelling framework that leads to robust MO optimisation.

\subsection{Process simulation}

Simulation of the processing is a necessary step towards the optimisation of manufacturing. Simulation tools have been developed in order to address the solution of each stage of the overall process. The winding/draping/forming stage, in which reinforcement is laid on a tool in its final shape, has been treated 
either by using kinematic models which assume inextensible tows that rotate freely at crossover points and have only pure shear as the active deformation mechanism [6-9] or by means of Finite Element (FE) modelling which can predict the overall mechanical response of the reinforcement but has the drawback of a higher computational cost [10-13]. The filling stage, in which dry fabrics are impregnated with liquid resin, has been addressed by solving Darcy's law which governs the resin flow through porous media [1418]. Darcy's law is as follows:

$$
\bar{u}=-\frac{\widetilde{K}}{\eta} \cdot \nabla P
$$

where $\tilde{K}$ is the permeability tensor of the preform which depends on the geometry and architecture of the fabric, $P$ is the pressure, $\eta$ is the viscosity and $\bar{u}$ is the velocity vector.

Consolidation simulation has been used to predict the distribution of the applied pressure on the resin and reinforcement and predict the evolution of thickness and fibre volume fraction [19-25]. The curing stage, which involves material state change of the matrix from liquid to glass, is a heat transfer problem with heat generation due to the chemical reaction occurring in the resin during the process [26-30]. The heat generated due to the reaction is quantified using a cure kinetics model of the resin [31, 32].

The heat transfer equation to solve the problem is the following:

$$
\rho_{c} c_{p c} \frac{\partial T}{\partial t}=\nabla\left(k_{c} \nabla T\right)+\rho_{r} v_{r} H_{r} \frac{d \alpha}{d t}
$$

Here $\rho_{c}, c_{p c}$ and $k_{c}$ represent the density, specific heat capacity and thermal conductivity of the composite, whilst $T$ is the temperature, $\rho_{r}$ is the density of the resin, $v_{r}$ the resin volume fraction, $H_{r}$ the total heat generated by the resin and $\frac{d \alpha}{d t}$ the reaction rate of the resin.

Solution of the heat transfer problem coupled with mechanical analysis has also been addressed in literature to predict the generation of process induced stresses and distortion [33-39].

\subsection{Winding, draping and forming stage optimisation}

Optimisation of the filament winding process has been carried out addressing the winding path and pretension. Typical constraints applied are: target winding angles, no bridging and no slippage. The target of the process is to produce fibre paths as closely as possible to a nominal design since poor compliance to nominal lay-up values can lead to lower mechanical performance. Fig. 6 shows a time line 
of the optimisation effort on the topic.

An optimal pre-load tension distribution has been found for the winding of cylindrical and spherical pressure vessels using a gradient technique in order to minimise the slippage of fibres [40]. The optimal winding path has been determined applying dynamic programming to minimise process time, taking into account constraints with respect to maximum winding speed and acceleration [41]. Minimisation of winding cost has been carried out by means of a GA and a random search algorithm showing that the GA outperforms a random search algorithm solution by bringing a $70 \%$ further reduction in process cost [42]. MO optimisation of the filament winding process has not been attempted in the literature.

In forming, optimal holding force profiles have been investigated to minimise the occurrence of wrinkling using GAs. Comparison between optimised holding force profiles with uniform force profiles showed that optimised profiles result in the elimination or reduction of concentrated buckling of tows [43, 44]. The optimal in plane tension to minimise wrinkles has been achieved by means of optimal blank holders arrangement achieving about 50\% reduction in wrinkles formation [45]. The optimisation of dimensions of rigid blocks (risers) has been addressed to minimise wrinkles formation during forming [46]. The optimal selection of draping starting position and direction for the minimisation of process cost and weight has been addressed in the case of a curved C-spar using a gradient based technique showing that the minimisation of material consumption leads to minimum process cost, whilst minimisation of weight always leads to higher process cost [47]. MO optimisation of draping has been undertaken aiming to minimise the maximum absolute shear angle and the average shear angle using a GA using pre-shear, drape starting point and draping direction as design parameters [48]. This setup leads to $30 \%$ reduction in computational time compared to an exhaustive search and a more accurate solution and design space exploration [48].

The research efforts to date on draping/forming and filament winding process optimisation have focussed on the process itself. However, the success of stages following draping (i.e. filling and curing) depends strongly on the accuracy and quality of the draping stage. As a consequence future research optimisation efforts should address the optimisation of draping parameters to minimise filling and curing related objectives so that a clear link between stages could be established.

\subsection{Filling stage optimisation for LCM}

The aim of optimising the filling stage of LCM is to achieve satisfactory impregnation of the dry 
reinforcement without compromising the duration of the process, which eventually affects process cost. The design parameters are the gate and vent locations, the filling temperature profile and the injection rate and pressure. A poor selection of these parameters can lead to process failures or defects that affect part quality. Fig. 7 illustrates the time line of the optimisation effort on the topic.

The optimisation of the filling stage of LCM processing has addressed both quality and cost related objectives. Single Objective (SO) optimisation dealing with minimisation of dry spots and micro/macro voids has been investigated for Resin Transfer Moulding (RTM) and Resin Injection under Flexible Tooling (RIFT). Significant reductions in void content can be achieved throughout the parts when an optimised injection rate profile is applied [49]. A distance based fitness function has been implemented to improve the filling pattern and to minimise dry spots by finding the optimal number and/or configuration of gates and vents [50-52]. Furthermore, cost related objectives such as filling time, have been considered in SO optimisation of the RTM process. Optimal gates number and/or locations have been investigated to minimise filling time [53-56]. The presence of many local minima in the problem landscape has driven the algorithm choice toward nature inspired techniques, mainly GAs. The combination of gradient based methods with GAs results in an $85 \%$ reduction in computational time compared to GAs alone and almost $60 \%$ reduction in filling time for the filling of a plate with an insert compared to a standard case [53]. The optimisation of gate locations for the filling of an uneven plate brought about 50\% reduction in filling time [55], whilst a gate optimisation combined with a sequential injection strategy resulted in reduction in filling time by $85 \%$ compared to a standard solution [54]. An optimisation methodology based on the Centroidal Voronoi Diagram used to minimise filling time by optimal gate placement achieved about $90 \%$ reduction in number of simulations required at the cost of a $2 \%$ increase in filling time compared to a GA [56]. The anticipation of the flow pattern becomes very difficult as the complexity of the part increases. Incorrect selection of gates and vents can lead to dry spots and voids which in turn lead to rejection of the part. The capability of addressing the location of gates and vents at design stage can minimise the risk of process failure.

However, industrial practice is driven by two factors: cost and quality. The two drivers cannot be separated and need to be addressed together. Therefore, attempts to treat the filling problem in a more comprehensive way have been made by computing weighted fitness functions accounting for multiple objectives [57-64]. Weighted SO fitness functions considering dry spots, voids formation and filling time 
have been used with zero order search algorithms leading to the identification of optimal gate locations [60-64]. The optimal vent configuration problem for a given gate configuration has been addressed and successfully solved in the presence of disturbances, such as racetracking, using a combinatorial search [57] and a map-based exhaustive search [58]. The problem of finding the optimal single gate and multiple vents configuration to minimise filling time and dry spots in the presence of racetracking has also been addressed leading to a reduction in dry spots of about $45 \%$ [59] compared to a fixed gate location [57, 58]. Minimisation of the through thickness temperature gradient and filling time has been carried out using a weighted fitness function to optimise the filling temperature and the resin injection temperature achieving reduction of the aggregated objective value by about 30\% [65]. A MO optimisation methodology has been built for optimising RTM gate locations to minimise both filling time and void content successfully identifying the Pareto set and the corresponding efficient front highlighting the competitive nature of the objectives selected [66]. Multi objective optimisation of RTM targeting optimal gate locations to minimise resin waste and weld line area (i.e. the area originating from two colliding resin fronts) alongside filling time and dry spots has been addressed yielding a Pareto set of solutions in which filling time and weld line volume are negatively correlated and dry spots and resin wastage are positively correlated [67]. Fig. 8 illustrates the efficient set evolution at different generations for a flat plate (a) and rib (b) model; a trade-off between filling time (i.e. cost objective) and weld line area (i.e. quality objective) exist. A MO methodology linking a GA with a commercial FE solver was developed to minimise both filling time and degree of cure at the end of the filling stage by optimising gate locations and non-isothermal temperature profiles $[68,69]$. The Pareto set showed that reduction of $66 \%$ in filling time and $15 \%$ in degree of cure at the end fillingis possible compared to a standard isothermal filling stage [68]. The findings highlight that standard isothermal profile suggested in material datasheet tend to be too conservative and as consequence not optimal. The MO optimisation presented points out that improved solutions both in terms of process cost and quality exist and the MO framework can uncover them. Fig. 9 illustrates the convergence of the efficient set to the final Pareto set. The results show that a trade-off between filling time and maximum degree of cure at the end of the filling exists and provides the designer with a set of optimal solutions to choose from according to the application.

Optimal cure profiles to minimise process time accounting for consolidation constraints have been identified. Reduction in process time of about 50\% compared to a standard profile has been achieved 
[70]. Minimisation of an objective function considering consolidation time and temperature overshoot by identification of optimal cure cycles has been performed using a GA, reducing consolidation time by $67 \%$ compared to a standard cure cycle [71]. A GA has been used to identify optimal pressure profiles to minimise the difference from a target fibre volume fraction [72].

Up to date few works have addressed the problem of the filling stage in a MO setting. The results obtained are encouraging, suggesting that there is significant margin for improvement in both quality and cost related objectives. In the context of promoting the use of composites in high volume production applications analysis, of this type is essential. Future research should focus on this direction. In terms of optimisation parameters, the definition of non-isothermal filling profile highlighted that standard filling profiles do not exploit fully efficiency opportunities. In addition to this, surface convection coefficient should be considered at the design stage and possibly be part of the optimisation parameters. Variability has not been taken into account yet. Deterministic models fail to deal with the variability of the real industrial practice, therefore stochastic models accounting for permeability and viscosity uncertainty should be implemented in a robust optimisation framework.

\subsection{Curing stage optimisation}

\subsubsection{Pultrusion process}

The optimisation of the pultrusion process has been addressed mainly as a SO problem. The objectives addressed are both cost related, such as process time and energy consumption, and quality related, such as minimisation of degree of cure variation across the thickness or residual stress. The constraints adopted include the maximum temperature allowed within the part to avoid degradation of the resin and minimum degree of cure at the exit of the die. Poorly designed cure cycles can lead to a violent exothermic reaction that affects quality of the part and also induce thermal gradients and therefore degree of cure gradients through thickness. Fig. 10 presents the time line of the research efforts on pultrusion process.

A zero order search algorithm has been adopted and combined with a gradient based technique in a hybrid scheme to optimise the pulling speed and the temperature profile achieving a reduction in process cost of about $30 \%$ [73]. The objective of energy consumption minimisation has also been tackled to reduce process cost $[74,75]$. The optimisation sought optimal die temperatures to minimise energy consumption in a dual die pultrusion process, whilst the quality of the manufactured parts was ensured by applying a minimum degree of cure variation across the thickness allowed. A swarm particle algorithm 
was adopted for SO optimisation showing that it is possible to minimise energy consumption by lowering the temperature of the second heater and exploiting the heat released by the cure reaction triggered with the first heater temperature achieving a $25 \%$ reduction in energy consumption compared to a standard process $[74,75]$. Cure cycle optimisation has been carried out under uncertainty showing that minimum cure time increases when variability is taken into account $[76,77]$. The introduction of variability considerations into the optimisation loop is a necessary step toward robust optimisation. Robustness of manufacturing processes can only be addressed by implementing stochastic models in a rigorous optimisation framework. Understanding uncertainty generation and propagation can prevent process failures. Quality related objectives such as uniformity of cure through the thickness or minimum residual stresses have been addressed in SO optimisation of the pultrusion process. A gradient based optimiser has been used to minimise the degree of cure gradient across the thickness by optimising the pulling speed and the temperature profile of heaters placed along the die [78-80]. Introducing die cooling to the optimisation led to $75 \%$ improvement in cure uniformity compared to standard conditions, whilst highlighting that pulling speed and cooling die temperature play an important role in decreasing temperature overshoot [80]. Hybrid algorithms combining a GA with a gradient based technique [81] and a PSO algorithm [82] have been applied to optimise the heating profile to maximise the uniformity of the cure across the thickness achieving $85 \%$ [81] and 80\% [82] improvement compared to nominal solutions. An Artificial Neural Network (ANN) procedure has been used in combination with a GA to select the temperature profile and pulling speed to minimise the degree of cure variation across thickness, leading to a 50\% improvement $[83,84]$. An hybrid algorithm has been used to minimise the energy consumption of the pultrusion process by selecting the number of heaters and pulling speed leading to a $120 \%$ increase in productivity compared to standard processing [85]. Although, it is possible by applying constraints, to contain the outcomes of objectives not specifically addressed by the optimisation, SO objective optimisation does not address the challenges of the manufacturing process as a whole and its outcomes are not optimal trade-offs between them which is the reason why recent research efforts focus on MO optimisation and SO optimisation is being abandoned. A MO variant of the problem aiming to identify the optimal number of heaters, their dimensions and the temperature profile along the die in order to maximise pulling speed and minimise energy consumption subject to maximum temperature and minimum final degree of cure constraints has led to $70 \%$ reduction in energy consumption and $100 \%$ 
increase in pulling speed $[86,87]$. The MO problem of maximising pulling speed and degree of cure by optimising first and second heater temperature profiles and initial resin temperature has been tackled. A surrogate model has been implemented to speed up the computational time. Compared to initial configuration a $20 \%$ increase in pulling speed and $7 \%$ in degree of cure has been reached [88]. In a follow-up work, the maximisation of the pulling speed was addressed together with the minimisation of the spring-in angle of a C-section, using the previous optimisation parameters. Compared to the initial configuration, optimal solutions in the Pareto front led to $18 \%$ pulling speed increase and $46 \%$ decrease in spring-in angle [89].

\subsubsection{Batch processes}

The optimisation of the cure stage of batch processes such as autoclave and LCM has been addressed both as a minimisation problem for cost related objectives (e.g. cure time) and quality related objectives (e.g. temperature overshoot or residual stresses). Typical constraints for the batch process optimisation are the maximum temperature allowed during the cure and minimum degree of cure reached within the part at the end of the process. Fig. 11 presents the time line of the research efforts on batch processes.

Starting from a recommended cure profile, a near optimal cure profile has been identified using a zero order search algorithm for thick composite laminates leading to about $40 \%$ reduction in process time and also to about $60 \%$ reduction in overshoot temperature [90, 91]. The implementation of a gradient based technique to the same cure problem results in a further $60 \%$ reduction in cure time [92]. Different combinations of zero order search algorithms have also been explored to design optimal cure profiles minimising process time $[93,94]$. SO optimisation of thick components showed that the introduction of a three dwell cure profile can bring about a $60 \%$ reduction in process time compared to a two dwell profile [95]. The application of optimisation to identify optimal cure profiles becomes critical for increased thicknesses [70, 95, 96]. GA and PSO have been implemented to minimise the cure time achieving a reduction of about $25 \%$ compared to standard profiles $[97,98]$ whilst the implementation of a GA in combination with ANN led to about $40 \%$ reduction [99].

Similarly, optimal cure profiles have been sought to minimise residual stresses and temperature overshoot. The effect of different cure profiles on residual stress formation has been investigated and reduction in residual stresses in the range of 25-30\% achieved [100]. Optimal parameters for curing of 
composite laminates to maximise material properties have been identified by means of gradient based techniques achieving improvements in the order of 10-20\% [101, 102]. Optimal cure profiles to minimise residual stresses have been identified using graphical methods and the sensitivity of process stresses to cycle parameters achieving reduction of about $30 \%[103,104]$. The minimisation of residual stress has also been tackled by setting SO problems aimed to minimise the temperature gradients in the through thickness direction. Different gradient based techniques have been successfully implemented reaching a quasi-uniform temperature distribution through the thickness [105, 106].

Weighted objectives have been used to account for both quality and cost related objectives in the process of cure. The optimisation problem constitutes still a SO problem; however, benefits in both objectives can be achieved. A weighted fitness function has been designed to account for minimum cycle time, maximum final degree of cure and minimum residual stresses [107, 108]. A comparison between gradient based techniques and ES to identify optimal cure cycles for the minimisation of a weighted fitness functions including cure time and uniformity through the thickness terms showed that the hybrid algorithm generates better overall performance in terms of CPU time [109, 110]. Optimal cure cycles identified with ES, when variability in the input parameters was considered, led to $80 \%$ lower rejection rate compared to those with cure cycles not accounting for input variability [111]. A GA optimiser has been used with a weighted fitness function taking into account cure time, temperature and cure gradients through the thickness to determine optimal cure cycle. Application of the cure cycle found led to negligible temperature and degree of through thickness cure gradients [112]. Optimal cure cycle design taking into account both cure time and final curvature due to distortion has also been addressed using a GA and a weighted objectives function leading to about $10 \%$ reduction in curvature associated with an increase in cure time by about $40 \%$ [113]. Minimisation of spring-in distortion has been achieved by optimising the mould angle using a gradient based optimisation techniques achieving improvements of about $80 \%[114,115]$. SO optimisation through definition of weighted fitness functions requires previous knowledge of the landscape of the problem and therefore are limited to the specific applications. MO optimisation frees the designer from required a priori knowledge of the process and provides a set of optimal solutions that can span different cost/performance applications.

A MO solution of the curing process has been carried out with a GA considering cure time and overshoot temperature as objectives and obtaining a Pareto set including process designs with significant 
benefits in both objectives [116-118]. Fig. 12 shows a typical design landscapes for a cure process. The figure shows the complexity of the landscape at hand. The presence of several local minima calls for the use of zero order search methods (i.e. GA) to avoid getting trapped in local minima. Also, using a MO optimisation framework degree of cure inhomogeneity and curing time has been successfully minimised and relevant trade-offs identified [119]. In the case of VARTM processing, the addition of convection coefficient as optimisation parameter showed that further improvements can be obtained in terms of reduction in process time (30\%) and degree of cure gradient through thickness $(65 \%)$ when insulation is applied to the vacuum bag side compared to when standard natural convection is present [120]. The optimisation of the ramp up phase of the VARTM process has been undertaken by means of polyline temperature patterns to minimise cure time and degree of cure gradient; showing that two (or more) node designs are adequate to lead to optimal solutions [121]. A stochastic multi objective optimisation has been applied to identify robust Pareto sets containing optimal cure cycle designs able to reduce cure time and maximum overshoot temperature by $40 \%$ compared to standard solutions whilst reducing variability by about 20\% [122]. Fig. 13 reports the comparison between deterministic and stochastic Pareto fronts. The objectives to minimise are cure time, maximum temperature overshoot and the two corresponding variabilities. The addition of variability makes the Pareto front shift toward longer cure time and higher temperature overshoot in search of more stable solutions. The findings from MO optimisation and robust MO optimisation highlight that cure profile recommended by product datasheets do not lead to optimal solutions.

Research efforts in this area should move towards direct minimisation of residual stresses. With regard to optimisation parameters, convection coefficient needs to be part of the design domain as it could act as exothermic reaction regulator. The idea of MO optimisation for optimal solutions of the cure process is more established compared to the other two stages. Research has also addressed the topic of variability and robust optimisation; however, further work is needed on this. The implementation of robust MO optimisation will lead to lower part rejection rates and re-manufacture, shorter production times and better performance rendering the composite manufacturing practice more reliable, robust and environmentally sustainable. 


\subsection{Combination with sensing}

Recent trends in the optimisation of composite manufacturing processes include the integration of process monitoring with optimisation. Measurements acquired from sensors are utilised to enrich the process optimisation loop with data that can reduce uncertainty. The application of an inverse scheme based on Markov Chain Monte Carlo (MCMC) integrating flow monitoring data with a surrogate model of the filling stage of RTM process led to the online estimation of process outcomes and reduction of their uncertainties [123]. A similar methodology aiming at a fast solution of the flow through porous media problem coupled a 2D analytical model of the flow through porous media with pressure sensors data leading to accurate flow front monitoring, permeability mapping and wash-out prevention [124]. A methodology to infer fibre permeability on-line has been developed. Additionally the use of Statistical Process Control (SPC) charting technique detects change in local permeability on-line allowing to control injection pressure [125]. Surrogate model based optimisations have been implemented to solve the draping problem [126] and to allow robust optimisation of the cure process [122]. A Bayesian inverse problem has been implemented to improve the probabilistic knowledge of permeability during the RTM process. The procedure is able to update on-line the local permeability via inversion of measurements/observations achieving optimal control of the process[127].

\section{Conclusions}

Quality related objectives addressed for the winding/draping/forming stage include maximum shear angle, wrinkling, process time and process cost. Draping design parameters optimised include the draping direction and starting point, the pre-load tension and the holding force profile. The filling stage quality related objectives investigated address voids and dry spots as well as the filling time. The design parameters investigated for the filling stage include the injection rate, filling temperature profile and gates and vents locations and their numbers. The applied pressure profile has been used as design parameter for the consolidation problem. With respect to the cure stage, residual stresses and maximum overshoot temperature within the part have been addressed as the quality related objectives to be minimised, whilst the minimisation of the cure time has been attempted to minimise cost. Minimisation of spring-in and warpage deformation has also been addressed. The design variables considered for curing are the temperature profile and pulling speed for the particular case of the pultrusion process. 
The findings presented in this work highlight that multi-objective optimisation is part of the current trends in the field of composite manufacturing optimisation. This arises as a natural extension of the research work performed on single objective optimisation with constraints or the combination of different objectives in a weighted sum. The latter approach has the disadvantages of hindering the effect of each objective so that comprehensive conclusions regarding the objectives separately cannot be drawn. Using a pure multi-objective setting frees the designer from assigning unknown a priori benefits to the objective and allows two or more objectives to compete uncovering the optimal trade-offs governing the problem. Implementation of a MO optimisation strategy in standard industrial practice can provide the process designer with a complete spectrum of possible design choices to choose from. The Pareto front contains optimal design points for different end applications that can be selected depending on the risk preferences and process cost versus performance prioritisation associated with it. Furthermore, the complexity of the design landscapes, which have been shown to be in general multimodal, drives the selection towards nature-inspired algorithms, especially GAs, which have the ability to explore large part of the objective space without getting trapped in local minima. Consideration of variability and potential effects on the stability of solutions highlights the need to add to the existing framework stochastic analysis of the process involving process boundary conditions uncertainty and intrinsic material properties variability. A comprehensive description of the phenomena requires integration of stochastic simulation in the optimisation loop which will eventually lead to optimal solutions that are both efficient and robust.

\section{Acknowledgments}

This work was supported by the European Commission through FP7 project INFUCOMP (233926), the Engineering and Physical Sciences Research Council, through the Grant RPOACM (EP/K031430/1) and the ADEM Innovation Lab.

\section{References}

[1] Holland J. Adaptation in natural and artificial systems. Ann Arbor (MI): The University of Michigan Press; 1975.

[2] Kennedy J. The particle swarm: social adaptation of knowledge. Proceedings of 1997 IEEE International Conference on Evolutionary Computation (ICEC '97)1997. p. 303-8. 
[3] Kennedy J, Eberhart R. Particle swarm optimization. Proceedings of ICNN'95 - International Conference on Neural Networks1995. p. 1942-8 vol.4.

[4] Dorigo M, Gambardella LM. Ant colony system: a cooperative learning approach to the traveling salesman problem. IEEE Transactions on Evolutionary Computation. 1997;1(1):53-66.

[5] Dorigo M, Maniezzo V, Colorni A. Ant system: optimization by a colony of cooperating agents. IEEE Transactions on Systems, Man, and Cybernetics, Part B (Cybernetics). 1996;26(1):29-41.

[6] Bickerton S, Šimáček P, Guglielmi SE, Advani SG. Investigation of draping and its effects on the mold filling process during manufacturing of a compound curved composite part. Composites Part A: Applied Science and Manufacturing. 1997;28(9):801-16.

[7] Potluri P, Sharma S, Ramgulam R. Comprehensive drape modelling for moulding 3D textile preforms. Composites Part A: Applied Science and Manufacturing. 2001;32(10):1415-24.

[8] Tam AS, Gutowski TG. The kinematics for forming ideal aligned fibre composites into complex shapes. Composites Manufacturing. 1990;1(4):219-28.

[9] Trochu F, Hammami A, Benoit Y. Prediction of fibre orientation and net shape definition of complex composite parts. Composites Part A: Applied Science and Manufacturing. 1996;27(4):319-28.

[10] Cherouat A, Billoët JL. Mechanical and numerical modelling of composite manufacturing processes deep-drawing and laying-up of thin pre-impregnated woven fabrics. Journal of Materials Processing Technology. 2001;118(1):460-71.

[11] Dong L, Lekakou C, Bader MG. Processing of composites: simulations of the draping of fabrics with updated material behaviour law. Journal of Composite Materials. 2001;35(2):138-63.

[12] McEntee SP, ÓBrádaigh CM. Large deformation finite element modelling of single-curvature composite sheet forming with tool contact. Composites Part A: Applied Science and Manufacturing. 1998;29(1):207-13.

[13] Nguyen M, Herszberg I, Paton R. The shear properties of woven carbon fabric. Composite Structures. 1999;47(1):767-79.

[14] Gibson AG. Modification of Darcy's law to model mould interface effects in composites processing. Composites Manufacturing. 1992;3(2):113-8.

[15] Hamdan MH. Single-phase flow through porous channels a review of flow models and channel entry conditions. Applied Mathematics and Computation. 1994;62(2):203-22. 
[16] Maier RS, Rohaly TF, Advani SG, Fickie KD. A fast numerical method for isothermal resin transfer mold filling. International Journal for Numerical Methods in Engineering. 1996;39(8):1405-17.

[17] Shojaei A, Reza Ghaffarian S, Mohammad Hossein Karimian S. Three-dimensional process cycle simulation of composite parts manufactured by resin transfer molding. Composite Structures. 2004;65(3):381-90.

[18] Šimáček P, Advani SG. Role of acceleration forces in numerical simulation of mold filling processes in fibrous porous media. Composites Part A: Applied Science and Manufacturing. 2006;37(11):1970-82. [19] Gutowski TG, Morigaki T, Zhong C. The consolidation of laminate composites. Journal of Composite Materials. 1987;21(2):172-88.

[20] Li M, Tucker CL. Modeling and simulation of two-dimensional consolidation for thermoset matrix composites. Composites Part A: Applied Science and Manufacturing. 2002;33(6):877-92.

[21] Saunders RA, Lekakou C, Bader MG. Compression in the processing of polymer composites 1 . A mechanical and microstructural study for different glass fabrics and resins. Composites Science and Technology. 1999;59(7):983-93.

[22] Saunders RA, Lekakou C, Bader MG. Compression in the processing of polymer composites 2. Modelling of the viscoelastic compression of resin-impregnated fibre networks. Composites Science and Technology. 1999;59(10):1483-94.

[23] Trochu F, Gauvin R, Gao DM. Numerical analysis of the resin transfer molding process by the finite element method. Advances in Polymer Technology. 1993;12(4):329-42.

[24] Trochu F, Ruiz E, Achim V, Soukane S. Advanced numerical simulation of liquid composite molding for process analysis and optimization. Composites Part A: Applied Science and Manufacturing. 2006;37(6):890-902.

[25] Yan X. Consolidation and cure simulations for laminated composites. Journal of Composite Materials. 2006;40(20):1853-69.

[26] Blest DC, McKee S, Zulkifle AK, Marshall P. Curing simulation by autoclave resin infusion. Composites Science and Technology. 1999;59(16):2297-313.

[27] Ciriscioli PR, Springer GS, Lee WI. An expert system for autoclave curing of composites. Journal of Composite Materials. 1991;25(12):1542-87. 
[28] Hojjati M, Hoa SV. Curing simulation of thick thermosetting composites. Composites Manufacturing. 1994;5(3):159-69.

[29] Pitchumani R, Yao S-C. Non-dimensional analysis of an idealized thermoset composites manufacture. Journal of Composite Materials. 1993;27(6):613-36.

[30] Suratno BR, Ye L, Mai Y-W. Simulation of temperature and curing profiles in pultruded composite rods. Composites Science and Technology. 1998;58(2):191-7.

[31] Dusi MR, Lee WI, Ciriscioli PR, Springer GS. Cure kinetics and viscosity of fiberite 976 resin. Journal of Composite Materials. 1987;21(3):243-61.

[32] Karkanas PI, Partridge IK. Cure modeling and monitoring of epoxy/amine resin systems. I. Cure kinetics modeling. Journal of Applied Polymer Science. 2000;77(7):1419-31.

[33] Bogetti TA, Gillespie JW. Process-induced stress and deformation in thicksection thermoset composite laminates. Journal of Composite Materials. 1992;26(5):626-60.

[34] Guemes JA. Curing residual stresses and failure analysis in composite cylinders. Journal of Reinforced Plastics and Composites. 1994;13(5):408-19.

[35] Kim KS, Hahn HT. Residual stress development during processing of graphite/epoxy composites. Composites Science and Technology. 1989;36(2):121-32.

[36] Kim YK, White SR. Process-induced stress relaxation analysis of AS4/3501-6 laminate. Journal of Reinforced Plastics and Composites. 1997;16(1):2-16.

[37] Mohan R, Grentzer TH. Process simulation in thermoset composites for cure response and stress prediction. Journal of Reinforced Plastics and Composites. 1995;14(1):72-84.

[38] Plepys A, Vratsanos MS, Farris RJ. Determination of residual stresses using incremental linear elasticity. Composite Structures. 1994;27(1):51-6.

[39] White SR, Zhang Z. The effect of mandrel material on the processing-induced residual stresses in thick filament wound composite cylinders. Journal of Reinforced Plastics and Composites. 1993;12(6):698-711.

[40] Drozdov AD, Kalamkarov AL. Optimization of winding process for composite pressure vessels. International Journal of Pressure Vessels and Piping. 1995;62(1):69-81. 
[41] Koussios S, Bergsma OK, Beukers A. Filament winding: kinematics, collision control and process optimisation through application of dynamic programming. Composites Part A: Applied Science and Manufacturing. 2006;37(11):2088-104.

[42] Wilson E, Karr CL, Messimer S. Genetic algorithm optimization of a filament winding process modeled in WITNESS. Journal of Materials and Manufacturing Processes. 2003;18(3):223-39.

[43] Skordos AA, Monroi AC, Sutcliffe MPF. Drape optimisation in woven composite manufacturing. Proceeding of the $5^{\text {th }}$ international conference on inverse problem in engineering: theory and practice. Cambridge, UK 2006.

[44] Long A, Skordos AA, Harrison P, Clifford M, Sutcliffe MPF. Optimisation of sheet forming for textile composite using variable peripheral force. $27^{\text {th }}$ International conference SAMPE EUROPE. Paris, France 2006.

[45] Chen S, Harper L, Endruweit A, Warrior NA. Optimisation of forming process for highly drapeable fabrics. ICCM20 - 20th International conference on composite materials. Copenhagen, Denmark 2015. [46] Chen S, McGregor OPL, Harper LT, Endruweit A, Warrior NA. Optimisation of local in-plane constraining forces in double diaphragm forming. Composite Structures. 2018;201:570-81.

[47] Kaufmann M, Zenkert D, Åkermo M. Cost/weight optimization of composite prepreg structures for best draping strategy. Composites Part A: Applied Science and Manufacturing. 2010;41(4):464-72. [48] Skordos AA, Sutcliffe MPF, Klintworth JW, Adolfsson P. Multi objective optimisation of woven composite draping using genetic algorithm. $27^{\text {th }}$ International conference SAMPE EUROPE. Paris, France 2006.

[49] Ruiz E, Achim V, Soukane S, Trochu F, Bréard J. Optimization of injection flow rate to minimize micro/macro-voids formation in resin transfer molded composites. Composites Science and Technology. 2006;66(3-4):475-86.

[50] Jiang S, Zhang C, Wang B. Optimum arrangement of gate and vent locations for RTM process design using a mesh distance-based approach. Composites - Part A: Applied Science and Manufacturing. 2002;33(4):471-81.

[51] Kessels JFA, Jonker AS, Akkerman R. Optimising the flow pipe arrangement for resin infusion under flexible tooling. Composites Part A: Applied Science and Manufacturing. 2007;38(9):2076-85. 
[52] Ye X, Zhang C, Liang Z, Wang B. Heuristic algorithm for determining optimal gate and vent locations for RTM process design. Journal of Manufacturing Systems. 2004;23(4):267-77.

[53] Henz BJ, Mohan RV, Shires DR. A hybrid global-local approach for optimization of injection gate locations in liquid composite molding process simulations. Composites Part A: Applied Science and Manufacturing. 2007;38(8):1932-46.

[54] Kim BY, Nam GJ, Lee JW. Optimization of filling process in RTM using a genetic algorithm and experimental design method. Polymer Composites. 2002;23(1):72-86.

[55] Lin MY, Murphy MJ, Hahn HT. Resin transfer molding process optimization. Composites Part A: Applied Science and Manufacturing. 2000;31(4):361-71.

[56] Wang J, Simacek P, Advani SG. Use of centroidal voronoi diagram to find optimal gate locations to minimize mold filling time in resin transfer molding. Composites Part A: Applied Science and Manufacturing. 2016;87(Supplement C):243-55.

[57] Gokce A, Advani SG. Combinatorial search to optimize vent locations in the presence of disturbances in liquid composite molding processes. Materials and Manufacturing Processes. 2003;18(2):261-85.

[58] Gokce A, Advani SG. Vent location optimization using map-based exhaustive search in liquid composite molding processes. Materials and Manufacturing Processes. 2004;19(3):523-48.

[59] Gokce A, Advani SG. Simultaneous gate and vent location optimization in liquid composite molding processes. Composites Part A: Applied Science and Manufacturing. 2004;35(12):1419-32.

[60] Gokce A, Hsiao KT, Advani SG. Branch and bound search to optimize injection gate locations in liquid composite molding processes. Composites Part A: Applied Science and Manufacturing. 2002;33(9):1263-72.

[61] Jiang S, Zhang C, Wang B. A process performance index and its application to optimization of the RTM process. Polymer Composites. 2001;22(5):690-701.

[62] Luo J, Liang Z, Zhang C, Wang B. Optimum tooling design for resin transfer molding with virtual manufacturing and artificial intelligence. Composites Part A: Applied Science and Manufacturing. 2001;32(6):877-88.

[63] Mathur R, Advani SG, Fink BK. Use of genetic algorithms to optimize gate and vent locations for the resin transfer molding process. Polymer Composites. 1999;20(2):167-78. 
[64] Young WB. Gate location optimization in liquid composite molding using genetic algorithms. Journal of Composite Materials. 1994;28(12):1098-113.

[65] Yu HW, Young WB. Optimal design of process parameters for resin transfer molding. Journal of Composite Materials. 1997;31(11):1113-40.

[66] Ratle F, Achim V, Trochu F. Evolutionary operators for optimal gate location in liquid composite moulding. Applied Soft Computing. 2009;9(2):817-23.

[67] Okabe T, Oya Y, Yamamoto G, Sato J, Matsumiya T, Matsuzaki R, et al. Multi-objective optimization for resin transfer molding process. Composites Part A: Applied Science and Manufacturing. 2017;92:1-9.

[68] Struzziero G, Skordos AA. Multi-objective optimization of Resin Infusion. Advanced Manufacturing: Polymer \& Composites Science. 2019;5(1):17-28.

[69] Struzziero G, Skordos AA. Multi-objective infusion optimization in vacuum assisted resin transfer moulding (VARTM) using genetic algorithms. ICCM19 - 19th International conference on composite materials. Montreal, Canada 2013.

[70] Li M, Tucker CL, III. Optimal curing for thermoset matrix composites: thermochemical and consolidation considerations. Polymer Composites. 2002;23(5):739-57.

[71] Chang M-h, Chen C-l, Young W-B. Optimal design of the cure cycle for consolidation of thick composite laminates. Polymer Composites. 1996;17(5):743-50.

[72] Li M, Li Y, Zhang Z, Gu Y. Pressure window analysis for thin laminated composites in autoclave process. Polymer Composites. 2009;30(2):169-75.

[73] Coelho RML, Calado VMA. An optimization procedure for the pultrusion process based on a finite element formulation. Polymer Composites. 2002;23(3):329-41.

[74] Santos LS, Pagano RL, Biscaia EC, Calado VMA. Optimum heating configuration of pultrusion process. In: de Brito Alves RM, do Nascimento CAO, Biscaia EC, editors. Computer Aided Chemical Engineering: Elsevier; 2009. p. 705-10.

[75] Santos LS, Pagano RL, Calado VMA, Biscaia EC, Jr. Optimization of a pultrusion process using finite difference and particle swarm algorithms. Brazilian Journal of Chemical Engineering. 2015;32(2):543-53. 
[76] Acquah C, Datskov I, Mawardi A, Zhang F, Achenie LEK, Pitchumani R, et al. Optimization under uncertainty of a composite fabrication process using a deterministic one-stage approach. Computers and Chemical Engineering. 2006;30(6-7):947-60.

[77] Mawardi A, Pitchumani R. Cure cycle design for thermosetting-matrix composites fabrication under uncertainty. Annals of Operations Research. 2004;132(1):19-45.

[78] Li J, Joshi SC, Lam YC. Curing optimization for pultruded composite sections. Composites Science and Technology. 2002;62(3):457-67.

[79] Lam YC, Li J, Joshi SC. Simultaneous optimization of die-heating and pull-speed in pultrusion of thermosetting composites. Polymer Composites. 2003;24(1):199-209.

[80] Joshi SC, Lam YC, Win Tun U. Improved cure optimization in pultrusion with pre-heating and diecooler temperature. Composites Part A: Applied Science and Manufacturing. 2003;34(12):1151-9. [81] Carlone P, Palazzo GS, Pasquino R. Pultrusion manufacturing process development: Cure optimization by hybrid computational methods. Computers and Mathematics with Applications. 2007;53(9):1464-71.

[82] Costa Dias RdC, Santos LdS, Ouzia H, Schledjewski R. Improving degree of cure in pultrusion process by optimizing die-temperature. Materials Today Communications. 2018;17:362-70.

[83] Chen X, Jiang B, Zhou Z. Optimization of CFRP pultrusion process with NSGA-II and ANN. Advanced Materials Research. 2012;538-541:2705-11.

[84] Chen X, Xie H, Chen H, Zhang F. Optimization for CFRP pultrusion process based on genetic algorithm-neural network. International Journal of Material Forming. 2010;3(SUPPL. 2):1391-9. [85] Baran I, Tutum CC, Hattel JH. Optimization of the thermosetting pultrusion process by using hybrid and mixed integer genetic algorithms. Applied Composite Materials. 2013;20(4):449-63.

[86] Tutum CC, Baran I, Hattel JH. Utilizing multiple objectives for the optimization of the pultrusion process based on a thermo-chemical simulation. Key Engineering Materials2013. p. 2165-74.

[87] Tutum CC, Baran I, Deb K. Optimum design of pultrusion process via evolutionary multi-objective optimization. International Journal of Advanced Manufacturing Technology. 2014;72(9-12):1205-17. [88] Safonov A, Saratov A, Ushakov A. Numerical optimization and sensitivity analysis of pultrusion process parameters. ECCM17 - 17th European conference on composite materials. Munich, Germany 2016. 
[89] Safonov A, Bondarchuk D, Saratov A, Ushakov A, Akhatov I. Optimal process design for largescale pultrusion structures. ICCM21 - 21th International conference on composite materials. Xi'an, China 2017.

[90] Pillai VK, Beris AN, Dhurjati PS. Heuristics guided optimization of a batch autoclave curing process. Computers and Chemical Engineering. 1996;20(3):275-94.

[91] Pillai VK, Beris AN, Dhurjati PS. Implementation of model-based optimal temperature profiles for autoclave curing of composites using a knowledge-based system. Industrial \& Engineering Chemistry Research. 1994;33(10):2443-52.

[92] Rai N, Pitchumani R. Optimal cure cycles for the fabrication of thermosetting-matrix composites. Polymer Composites. 1997;18(4):566-81.

[93] Carlone P, Palazzo GS. A simulation based metaheuristic optimization of the thermal cure cycle of carbon-epoxy composite laminates. AIP Conference Proceedings2011. p. 5-10.

[94] Mawardi A, Pitchumani R. Optimal temperature and current cycles for curing of composites using embedded resistive heating elements. Journal of Heat Transfer. 2003;125(1):126-36.

[95] Li M, Zhu Q, Geubelle PH, Tucker III CL. Optimal curing for thermoset matrix composites: thermochemical considerations. Polymer Composites. 2001;22(1):118-31.

[96] Yang ZL, Lee S. Optimized curing of thick section composite laminates. Materials and Manufacturing Processes. 2001;16(4):541-60.

[97] Pagano RL, Calado VMA, Bezerra de Souza M, Biscaia EC. Proposal of an optimum cure cycle for filament winding process using a hybrid neural network - first principles model. Polymer Composites. 2014;35(7):1377-87.

[98] Skordos AA, Partridge IK. Inverse heat transfer for optimization and on-line thermal properties estimation in composites curing. Inverse Problems in Science and Engineering. 2004;12(2):157-72. [99] Aleksendrić D, Carlone P, Ćirović V. Optimization of the temperature-time curve for the curing process of thermoset matrix composites. Applied Composite Materials. 2016;23(5):1047-63.

[100] White SR, Hahn HT. Cure cycle optimization for the reduction of processing-induced residual stresses in composite materials. Journal of Composite Materials. 1993;27(14):1352-78.

[101] Kam TY, Lai FM, Sher HF. Optimal paramerers for curing graphite/epoxy composite laminates. Journal of Materials Processing Tech. 1995;48(1-4):357-63. 
[102] Kennedy GJ, Hansen JS. The hybrid-adjoint method: A semi-analytic gradient evaluation technique applied to composite cure cycle optimization. Optimization and Engineering. 2010;11(1):23-43.

[103] Gopal AK, Adali S, Verijenko VE. Optimal temperature profiles for minimum residual stress in the cure process of polymer composites. Composite Structures. 2000;48(1):99-106.

[104] Olivier P, Cottu JP. Optimisation of the co-curing of two different composites with the aim of minimising residual curing stress levels. Composites Science and Technology. 1998;58(5):645-51. [105] Bailleul JL, Sobotka V, Delaunay D, Jarny Y. Inverse algorithm for optimal processing of composite materials. Composites Part A: Applied Science and Manufacturing. 2003;34(8):695-708. [106] Jahromi PE, Shojaei A, Reza Pishvaie SM. Prediction and optimization of cure cycle of thick fiberreinforced composite parts using dynamic artificial neural networks. Journal of Reinforced Plastics and Composites. 2012;31(18):1201-15.

[107] Ruiz E, Trochu F. Comprehensive thermal optimization of liquid composite molding to reduce cycle time and processing stresses. Polymer Composites. 2005;26(2):209-30.

[108] Ruiz E, Trochu F. Multi-criteria thermal optimization in liquid composite molding to reduce processing stresses and cycle time. Composites Part A: Applied Science and Manufacturing. 2006;37(6 SPEC. ISS.):913-24.

[109] Pantelelis N, Vrouvakis T, Spentzas K. Cure cycle design for composite materials using computer simulation and optimisation tools. Forschung im Ingenieurwesen/Engineering Research. 2002;67(6):25462.

[110] Pantelelis NG. Optimised cure cycles for resin transfer moulding. Composites Science and Technology. 2003;63(2):249-64.

[111] Michaud DJ, Beris AN, Dhurjati PS. Thick-sectioned RTM composite manufacturing, Part II. Robust cure cycle optimization and control. Journal of Composite Materials. 2002;36(10):1201-32. [112] Vafayan M, Ghoreishy MHR, Abedini H, Beheshty MH. Development of an optimized thermal cure cycle for a complex-shape composite part using a coupled finite element/genetic algorithm technique. Iranian Polymer Journal (English Edition). 2015;24(6):459-69.

[113] Shah PH, Halls VA, Zheng JQ, Batra RC. Optimal cure cycle parameters for minimizing residual stresses in fiber-reinforced polymer composite laminates. Journal of Composite Materials.

2017;52(6):773-92. 
[114] Wucher B, Lani F, Pardoen T, Bailly C, Martiny P. Tooling geometry optimization for compensation of cure-induced distortions of a curved carbon/epoxy C-spar. Composites Part A: Applied Science and Manufacturing. 2014;56:27-35.

[115] Zhu Q, Geubelle PH. Dimensional accuracy of thermoset composites: Shape optimization. Journal of Composite Materials. 2002;36(6):647-72.

[116] Struzziero G, Skordos AA. Multi-objective optimisation of composites cure using genetic algorithms. ECCM15 - 15th European conference on composite materials. Venice, Italy 2012.

[117] Struzziero G, Skordos AA. Multi-objective optimisation of the cure of thick components. Composites Part A: Applied Science and Manufacturing. 2017;93:126-36.

[118] Struzziero G, Teuwen JJE. Optimal cure cycles for manufacturing of thick composite parts using multi-objective genetic algorithms. ECCM18 - 18th European conference on composite materials. Athens, Greece 2018.

[119] Matsuzaki R, Yokoyama R, Kobara T, Tachikawa T. Multi-objective curing optimization of carbon fiber composite materials using data assimilation and localized heating. Composites Part A: Applied Science and Manufacturing. 2019;119:61-72.

[120] Struzziero G, Teuwen JJE. Effect of convection coefficient and thickness on optimal cure cycles for the manufacturing of wind turbine components using VARTM. Composites Part A: Applied Science and Manufacturing. 2019;123:25-36.

[121] Kosaka T, Ueyama G, Kusukawa K. Optimization of curing temperature patterns for FRP plate with uneven degree-of-cure distribution. ICCM21 - 21th International conference on composite materials. Xi'an, China 2017.

[122] Tifkitsis KI, Mesogitis TS, Struzziero G, Skordos AA. Stochastic multi-objective optimisation of the cure process of thick laminates. Composites Part A: Applied Science and Manufacturing. 2018;112:383-94.

[123] Tifkitsis K, Skordos AA. Real time uncertainty estimation in flow processes of composites manufacturing. The 14th International Conference on Flow Processing in Composite Materials (FPCM14). Lulea, Sweden 2018. 
[124] Di Fratta C, Koutsoukis G, Ermanni P. Investigation of a cost-effective system for on-line flow monitoring and quality control in resin transfer molding. ICCM20 - 20th International conference on composite materials. Copenhagen, Denmark 2015.

[125] Wei B-J, Chang Y-S, Yao Y, Fang J. Online estimation and monitoring of local permeability in resin transfer molding. Polymer Composites. 2016;37(4):1249-58.

[126] Pfrommer J, Zimmerling C, Liu J, Kärger L, Henning F, Beyerer J. Optimisation of manufacturing process parameters using deep neural networks as surrogate models. Procedia CIRP. 2018;72:426-31.

[127] Iglesias M, Park M, Tretyakov MV. Bayesian inversion in resin transfer molding. Inverse Problems. 2018;34(10):105002. 


\section{Figure legend}

Fig. 1 Relationship between process design parameters and defect generation

Fig. 2 GA functioning

Fig. 3 Pareto archive update

Fig. 4 Composite process optimisation objectives landscape

Fig. 5 Time line depicting the milestones in numerical optimisation of composite manufacturing

Fig. 6 Time line depicting the research efforts in numerical optimisation of filament winding, draping and forming process

Fig. 7 Time line depicting the research efforts in numerical optimisation of LCM process

Fig. 8 Fill time and weld line efficient front convergence a) flat plate b) rib model [67]

Fig. 9 Pareto set at different generations illustrating the trade-off between filling time and maximum degree of cure at the end of the filling for a VARTM process [68]

Fig. 10 Time line depicting the research efforts in numerical optimisation of pultrusion process

Fig. 11 Time line depicting the research efforts in numerical optimisation of batch processes

Fig. 12 Design space analysis landscape of the cure process: a) temperature overshoot as a function of first dwell temperature and ramp rate; b) process time as a function of first dwell temperature and ramp rate [117].

Fig. 13 Pareto front of stochastic and deterministic multi-objective optimisation [122] 


\section{Table legend}

Table 1 Benefits and drawbacks of gradient based technique vs zero search methods 
Winding/Draping/Forming

design parameters:

- Pre-load tension

- Holding force profile

- Pre-shear

- Direction

- Starting point

Starting point

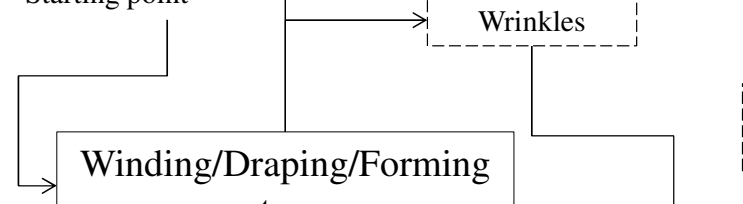

stage

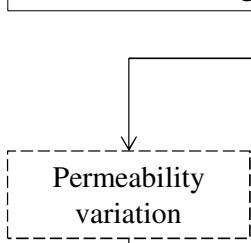

Misalignment

Shear deformation
Fibre volume

fraction/Thickness variation

Curing design parameters:

- Pulling speed

- Temperature profile

- Tool geometry

\section{Curing stage}

Thermal properties variation

Residual stresses
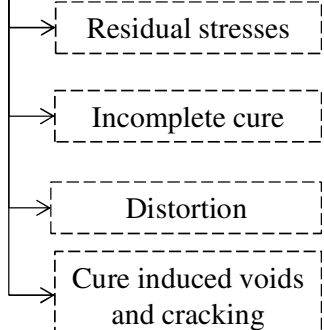

Filling/Consolidation stage

Filling design parameters:

- Injection rate/pressure

- Mould filling temperature profile

- Gates/vents locations

- Gates/vents numbers

- Pressure profile

Fig. 1 Relationship between process design parameters and defect generation

Table 1 Benefits and drawbacks of gradient based technique vs zero search methods

\begin{tabular}{|c|c|c|}
\hline Algorithm & Benefits & Drawbacks \\
\hline Gradient based & $\begin{array}{c}\checkmark \quad \text { Fast convergence } \\
\checkmark \quad \text { Reaches global minimum } \\
\text { (dependent on accurate } \\
\text { initial conditions } \\
\text { selection) }\end{array}$ & $\begin{array}{c}\checkmark \quad \text { get trapped in local minima } \\
\checkmark \quad \text { highly dependent on initial } \\
\text { conditions } \\
\checkmark \quad \text { Necessity to know the landscape of } \\
\text { the problem }\end{array}$ \\
\hline Zero search & $\begin{array}{cc} & \text { Avoid local minima } \\
\checkmark & \text { Deals with any landscape } \\
\checkmark & \text { Insensitive to initial } \\
& \text { conditions }\end{array}$ & $\begin{array}{c}\checkmark \quad \text { Computationally expensive } \\
\checkmark \quad \text { Does not guarantee the reaching of } \\
\text { global minimum }\end{array}$ \\
\hline
\end{tabular}





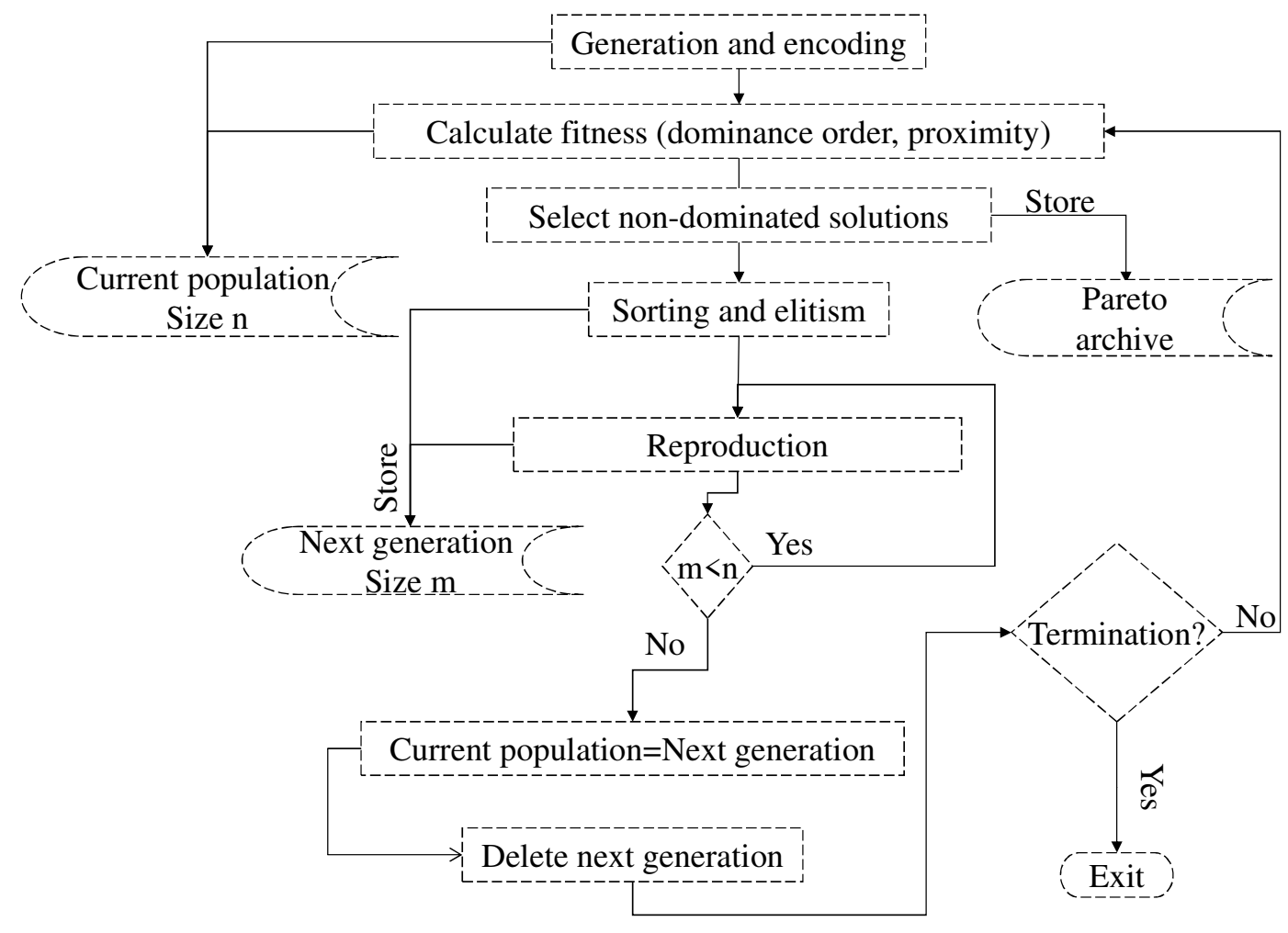

Fig. 2 GA functioning

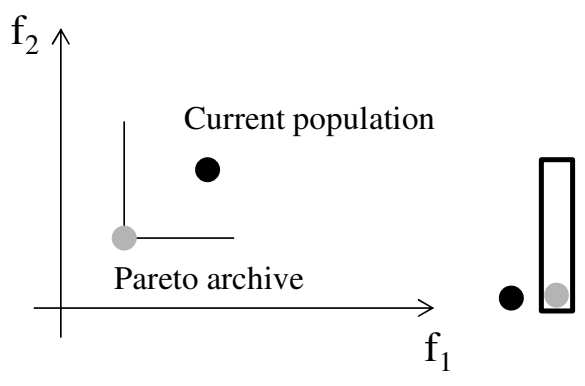

a)

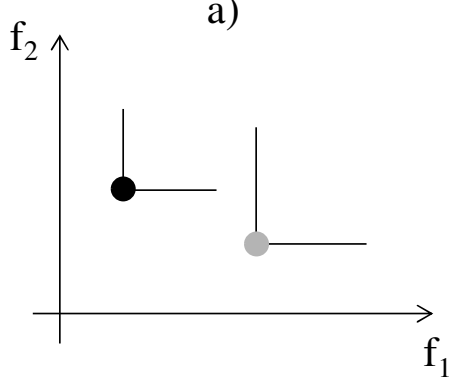

c)

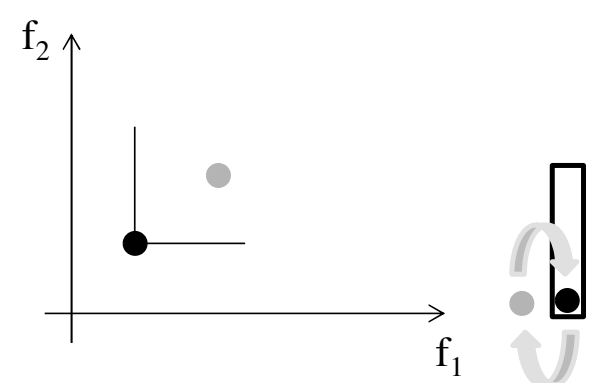

b)

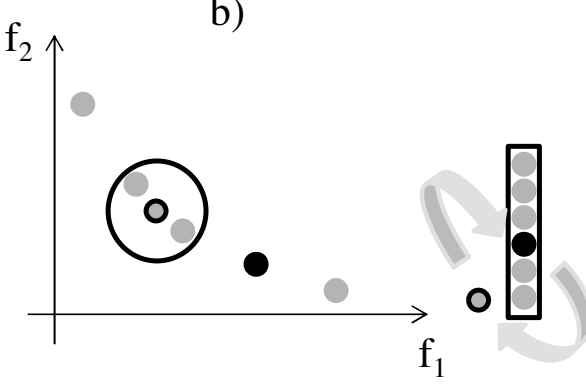

d)

Fig. 3 Pareto archive update 


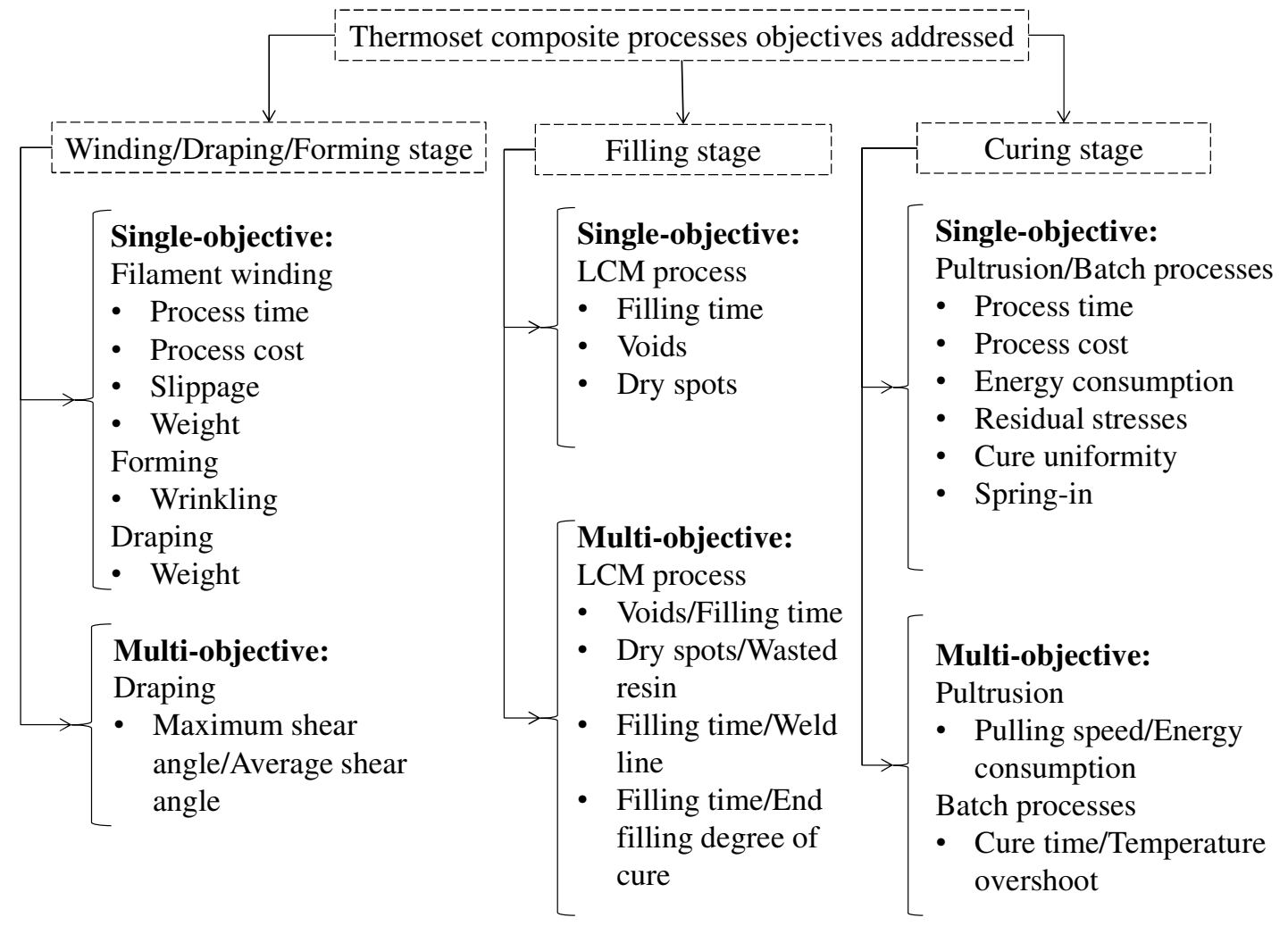

Fig. 4 Composite process optimisation objectives landscape 


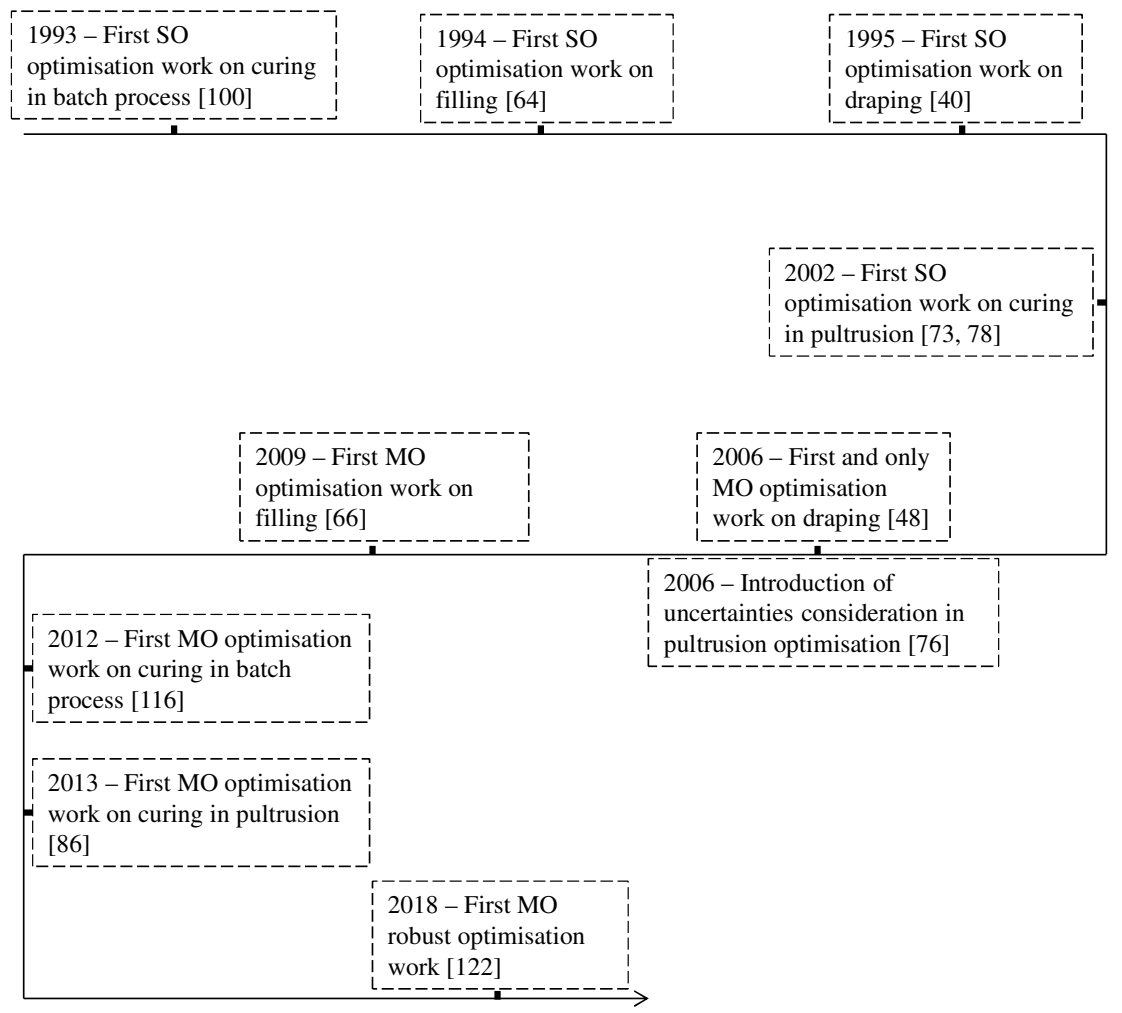

Fig. 5 Time line depicting the milestones in numerical optimisation of composite manufacturing

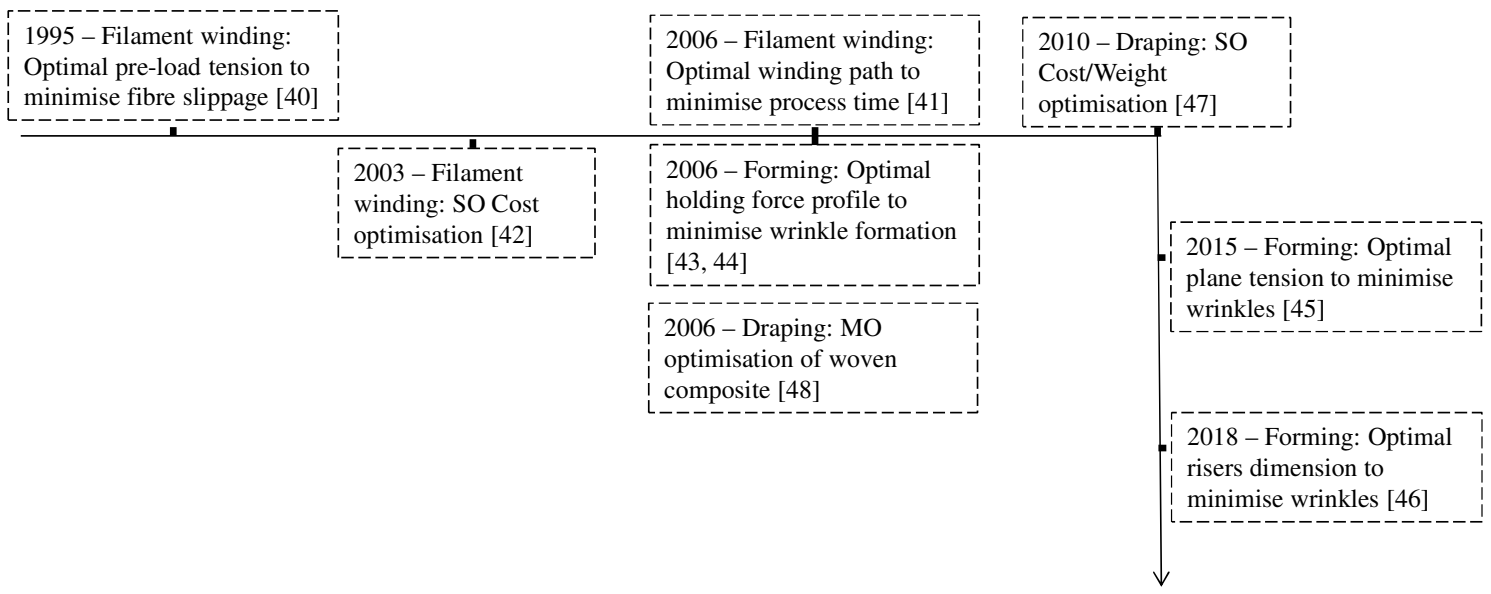

Fig. 6 Time line depicting the research efforts in numerical optimisation of filament winding, draping and forming process 


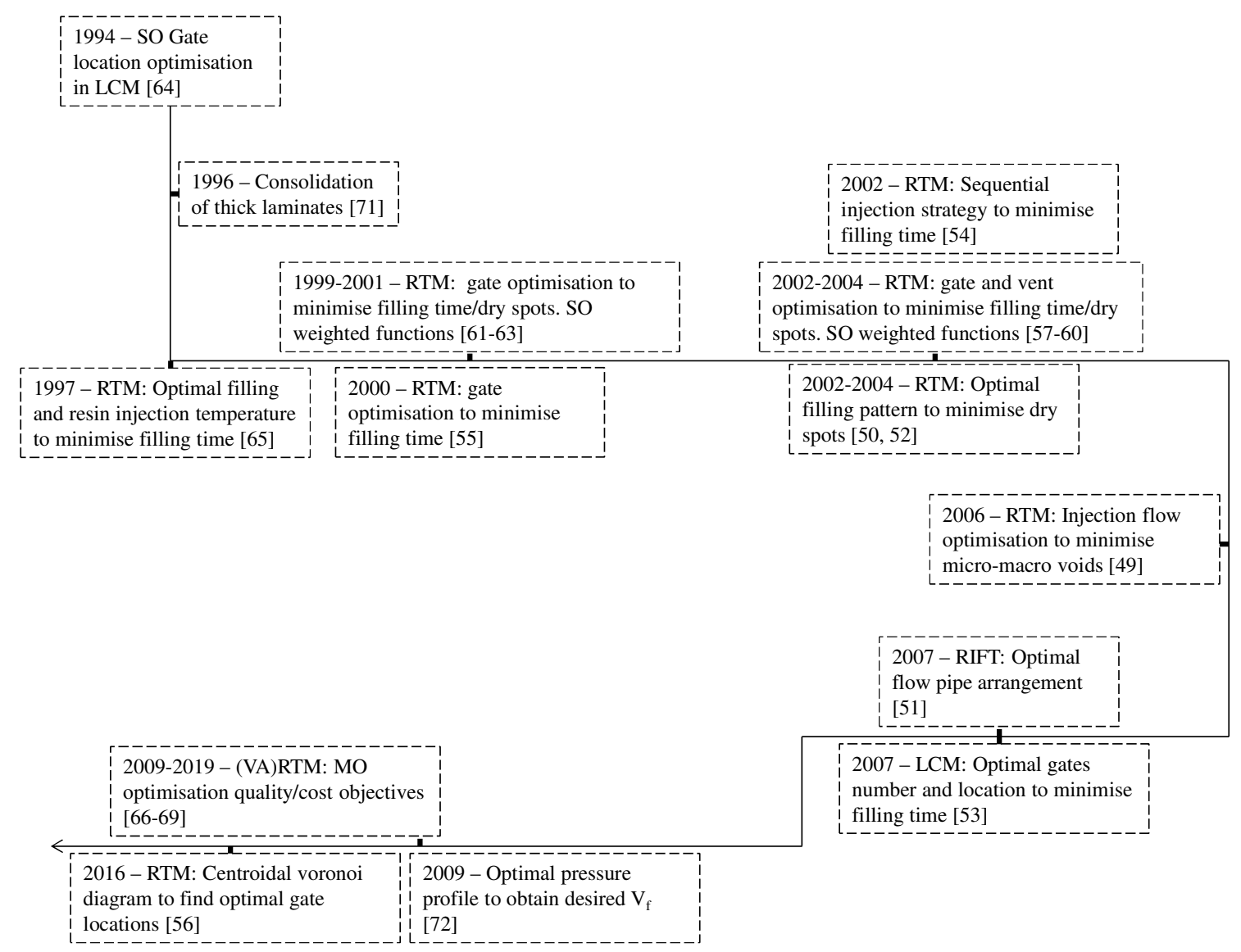

Fig. 7 Time line depicting the research efforts in numerical optimisation of LCM process

(a)

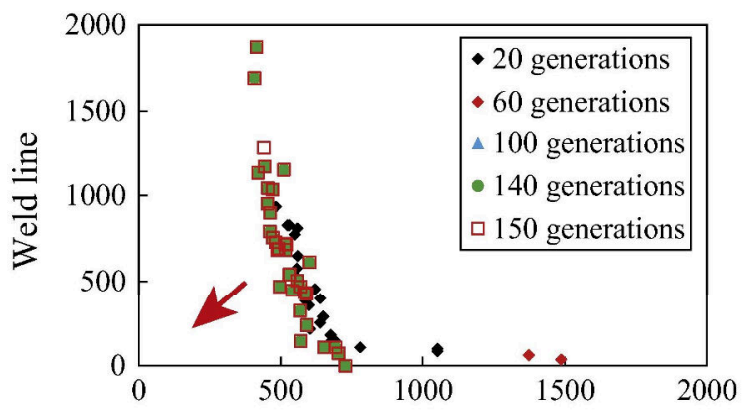

Fill time (b)

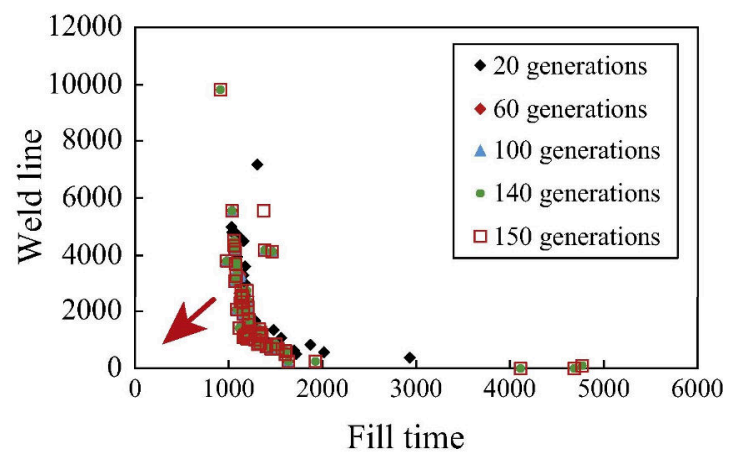

Fig. 8 Fill time and weld line efficient front convergence a) flat plate b) rib model [67] 


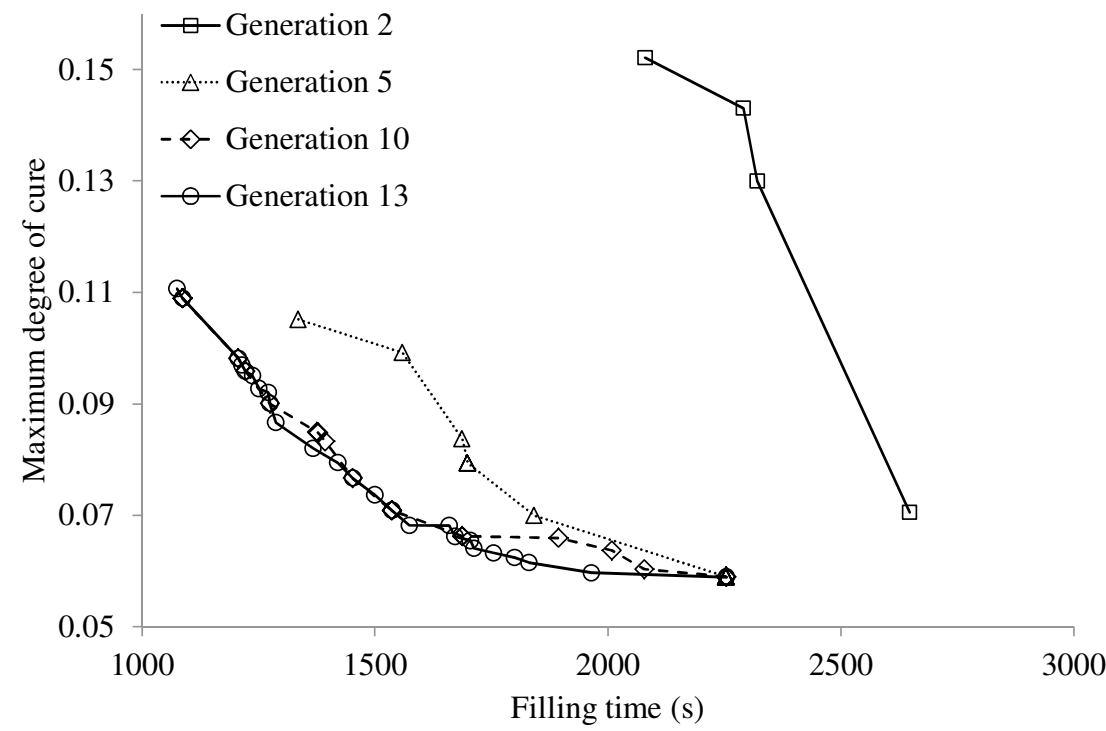

Fig. 9 Pareto set at different generations illustrating the trade-off between filling time and maximum degree of cure at the end of the filling for a VARTM process [68]

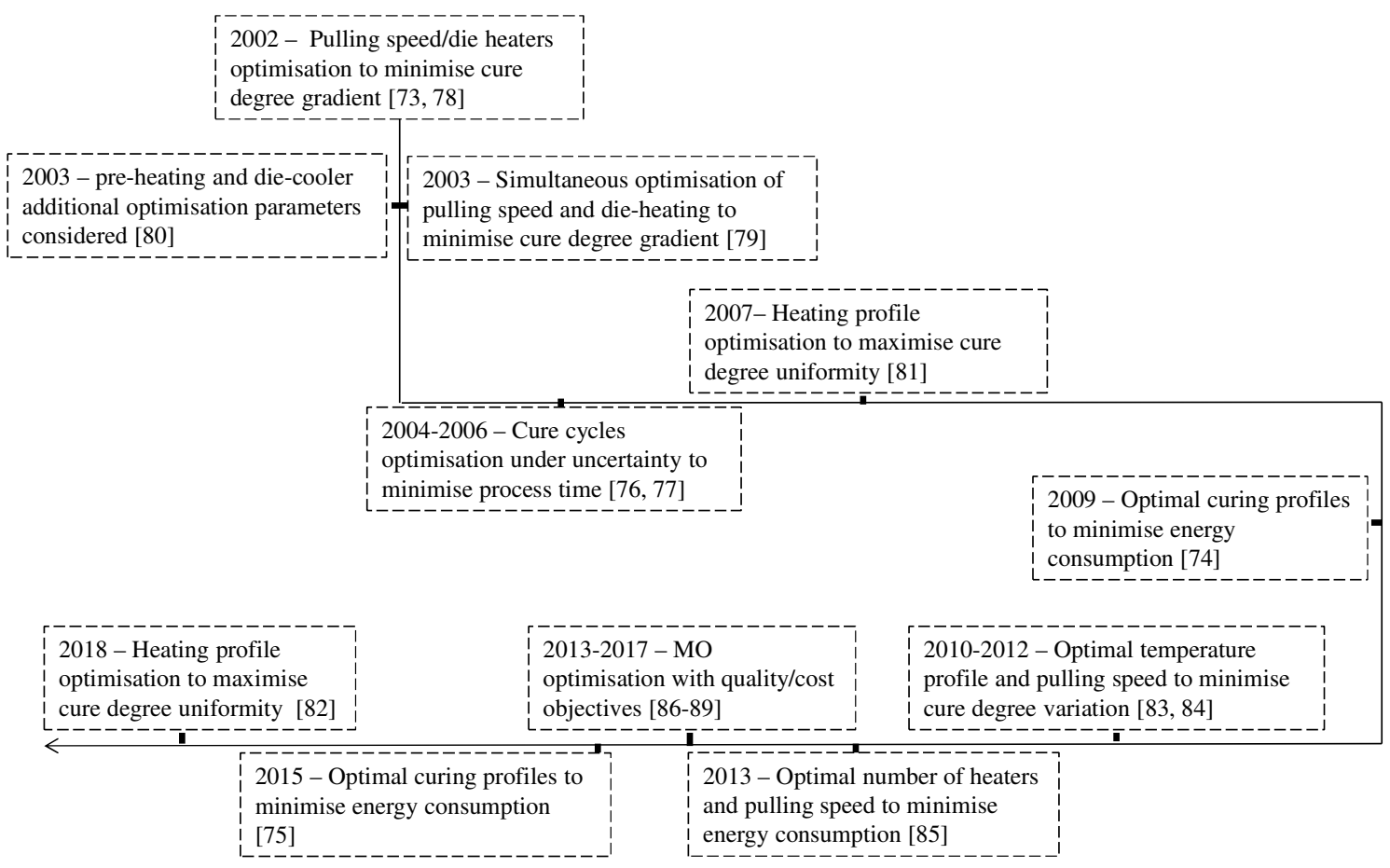

Fig. 10 Time line depicting the research efforts in numerical optimisation of pultrusion process 


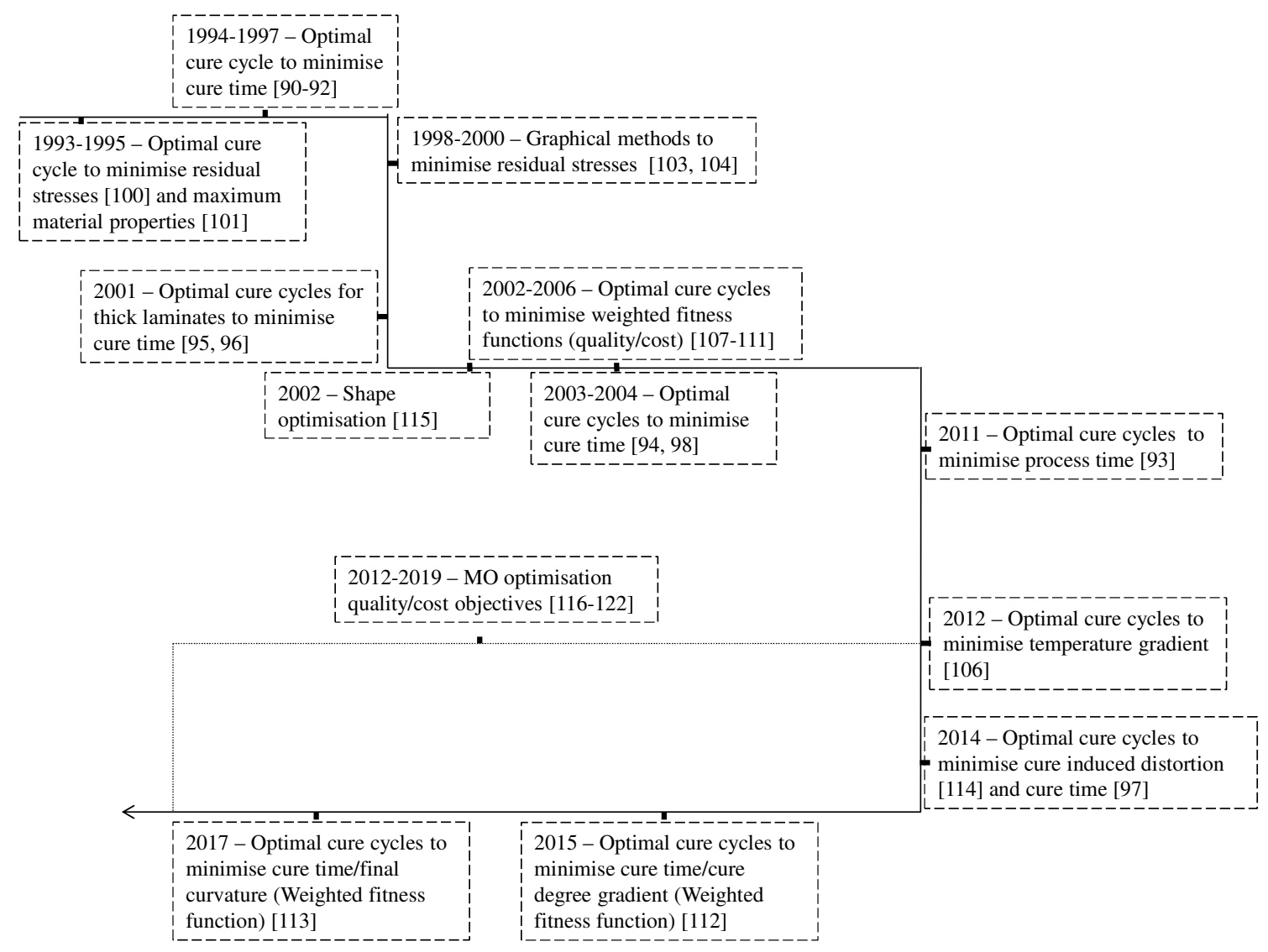

Fig. 11 Time line depicting the research efforts in numerical optimisation of batch process

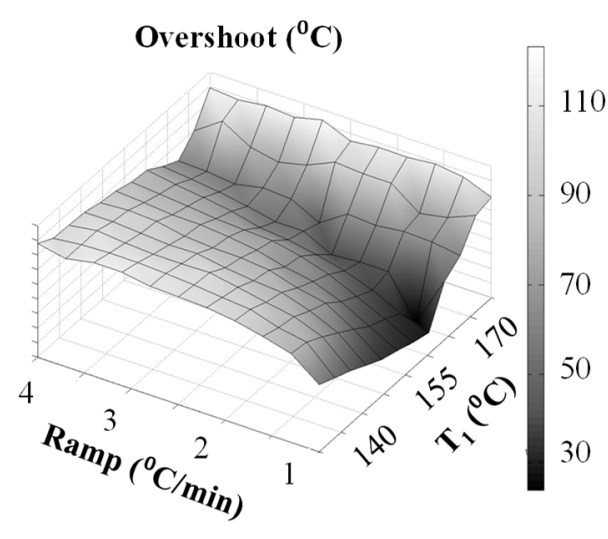

(a)

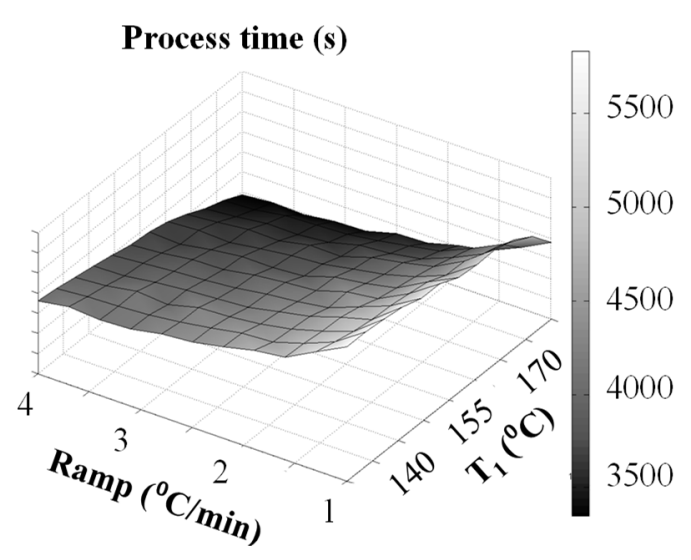

(b)

Fig. 12 Design space analysis landscape of the cure process: a) temperature overshoot as a function of first dwell temperature and ramp rate; b) process time as a function of first dwell temperature and ramp rate [117]. 


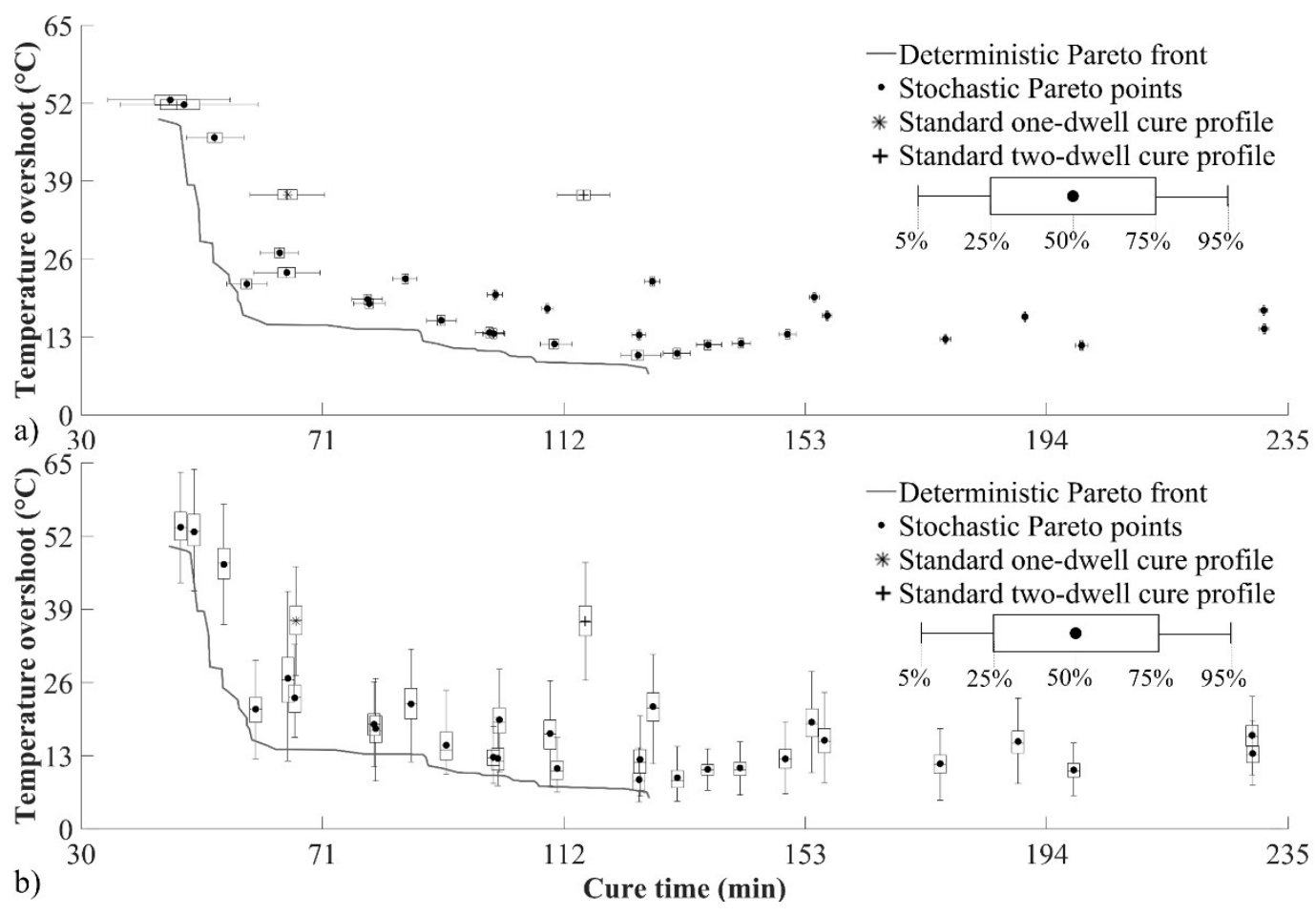

Fig. 13 Pareto front of stochastic and deterministic multi-objective optimisation [122] 
2019-06-25

Numerical optimisation of thermoset composites manufacturing processes: A review

Struzziero, Giacomo

Elsevier

Struzziero G, Teuwen JJE, Skordos AA. (2019) Numerical optimisation of thermoset composites manufacturing processes: A review. Composites Part A: Applied Science and Manufacturing, Volume 124, September 2019, Article number 105499

https://doi.org/10.1016/j.compositesa.2019.105499

Downloaded from Cranfield Library Services E-Repository 